\title{
A REFORMA DO ESTADO E MODERNIZAÇÃO DA GESTÃO DA EDUCAÇÃO BÁSICA NO CEARÁ (1995-2006)
}

\author{
J. F. P. RAMOS', L. M. LIRA ${ }^{2}$ e B. I. .B. SOARES ${ }^{3}$ \\ ${ }^{1}$ Universidade Estadual do Ceará \\ E-mail: ramosjeannette@yahoo.com.br ${ }^{1}$
}

Artigo submetido em março/2012 e aceito em maio/2012

\section{RESUMO}

A partir da Reforma ocorrida no Estado brasileiro podemos perceber as medidas que a mesma exerce sobre a política e a sociedade, a exemplo da descentralização, privatização, focalização e terceirização, visando a redução de gastos públicos. Neste contexto, este artigo tem como objetivo dissertar sobre a Reforma do Estado no Brasil e seus desdobramentos na modernização da gestão da Educação no Ceará, no recorte temporal de 1995-2006. Adentraremos na modernização da gestão, onde o planejamento é refuncionalizado. A gestão orientadora para os moldes da eficiência e execução de projetos é pautada sempre pelo discurso da gestão democrática, ao mesmo tempo em que é moldada na qualidade total, que se contrapõe a qualidade social. Para tanto, a pesquisa em desenvolvimento, de cunho bibliográfico e documental, tem por revista os autores BRESSER PEREIRA (1997) que define a Reforma do Estado como "[...] uma crise fiscal do Estado, uma crise do modo de intervenção do Estado no econômico e no social, e uma crise da forma burocrática de administrar o Estado" (p.09); VIDAL (2005); BEZERRA (2011); RAMOS (2010); SOUZA (2001); BEHRING (2003); BRITO (2010); RAMOS (2005); SHIROMA (2004); BALL (2002). A priori, a partir das análises, podemos perceber que a Reforma do Estado trouxe uma modernização na perspectiva gerencialista, resultando na descentralização, na gestão por resultados e na participação da comunidade escolar.

PALAVRAS-CHAVE: Estado, Educação, Modernização, Planejamento, Gestão.

\section{STATE REFORM AND MODERNIZATION OF BASIC EDUCATION MANAGEMENT IN CEARÁ (1995- 2006)}

\section{ABSTRACT}

From the Reformation occurred in the Brazilian State, we can realize the measures that the Reformation exerts on the politics and the society, such as decentralization, privatization, outsourcing and the targeting, aspiring to cause reduction in public spending. In this context, this article aims to discuss about the State Reform in Brazil and its consequences in the modernization of Education management modernization, where Education planning receives new functions. The management oriented for the pattern of efficiency and the implementation of projects are always guided by the concept of democratic management, while it is molded according to total quality, which is opposed to social quality. Thus, this research, is based on the authors BRESSER PEREIRA (1997) who defines the Reform of the State as "[...] a State fiscal crisis, a crisis in the State intervention way into the economic and social areas, and a crisis in the bureaucratic way of managing the State" (p. 09); VIDAL (2005); BEZERRA (2001); RAMOS (2010); SOUZA (2001) and BEHRING (2003); BRITO (2010); RAMOS (2005); SHIROMA (2004); BALL (2002). In the first place, from the analyzes, we can see that the Reform of the State resulted in modernization in the managerialist perspective, resulting in decentralization, in management by results and in the school community participation.

KEY-WORDS: State, Education, Modernization, Planning, Management. 


\section{TÍTULO DO ARTIGO}

\section{INTRODUÇÃO}

Com a redemocratização nacional, ocorrida a partir de 1985, destacava-se a necessidade de reformar o Estado brasileiro em consonância com as mudanças na organização sócio-política. Esse movimento, fruto da disputa ideológica, política e econômica, reorganiza o Estado, em meados dos anos 1990, que passa adotar políticas focalizadas em detrimento do princípio da universalidade, principalmente com relação à área social, através de reformas orientadas para o mercado.

Segundo Behring (2003, p. 176), para alcançar a sociedade moderna - com alocação de recursos eficiente e democracia - cabe uma estratégia voltada para o mercado, que use pragmaticamente o Estado para distribuir renda e promover a inovação tecnológica, numa sociedade heterogênea e dual, rompendo os círculos viciosos, econômico e político-social. Dessa forma, o Estado constituiu-se fundamental nos processos de mudança, reinventando seu poder regulador, seja através de instrumentos de planejamento que enfatizam a programação (ALBUQUERQUE, 2005) e o controle de resultados, seja por meio da desregulação controlada (BALL, 2001).

Em sintonia com a conjuntura mundial e nacional, o Estado do Ceará efetiva a revisão na estrutura e funcionamento do sistema educacional, pela reforma administrativa de cunho gerencial (CEARÁ,1996), pela revisão do marco legal (LDB no. 9396/96) e com a implementação de políticas públicas.

Nesse ínterim, a educação escolar passou a ser vista como o "remédio" perfeito para as mazelas sociais, frente às expectativas de melhorias das condições de vida dos indivíduos e superação das desigualdades sociais. No entanto, os processos de modernização da gestão do Estado e da educação passaram a ser disputados por referenciais antagônicos, são eles: gestão de qualidade total - GQT e a qualidade social.

Diante do que foi exposto, esta pesquisa busca analisar a reforma do Estado no Brasil e seus desdobramentos na modernização da gestão da educação básica no Ceará no período de 1995 a 2006, desvelando as contradições presentes no marco legal, nas diretrizes e na gestão da política educacional.

Para tanto, a pesquisa de cunho bibliográfico e documental, tem por objetivo revisitar a reforma do Estado, o planejamento e a gestão educacional dialogando com os seguintes autores: Bezerra (2011); Ramos (2002, 2004, 2010); Souza (2001); Behring (2003); Brito et alli (2010); Shiroma (2004) e Ball (2002). O estudo do tipo de caso instrumental na Escola Estadual de Ensino Médio Deputado Paulo Benevides tem com o objetivo esclarecer como o marco legal, as diretrizes e a gestão vem sendo materializadas na escola.

Partindo da assertiva de Bresser Pereira $(1997,09)$ que define a necessidade da Reforma do Estado como decorrente de "[...] uma crise fiscal do Estado, uma crise do modo de intervenção do Estado no econômico e no social, e uma crise da forma burocrática de administrar - Estado", iniciamos este artigo dissertando sobre a reforma do Estado brasileiro e suas implicações na educação escolar, para, em seguida, analisarmos alguns mecanismos de modernização da gestão da educação no Ceará e suas contradições no período de 1995 a 2006. 


\title{
I. A REFORMA DO ESTADO E SUAS IMPLICAÇÕES NA EDUCAÇÃO ESCOLAR
}

A crise econômica ocorrida em 1980 e definida como uma crise de Estado afetou economias de diversos países. Segundo Bresser Pereira (1997) o Estado entrou em crise e se transformou na principal causa da redução das taxas de crescimento econômico, da elevação das taxas de desemprego e do aumento da taxa de inflação que, desde então, ocorreram em todo o mundo.

Nas reformas ocorridas nesse período, resultantes da redefinição do papel do Estado na sociedade e da ascensão do neoliberalismo com suas propostas de ação mínima no setor social,

A descentralização, a privatização, a focalização e a terceirização constituem exemplos das novas formas de intervenção estatal (ou a minimização de sua atuação), mesmo no campo educacional. Esse modelo de Estado é intensamente influenciado pelo discurso econômico que prega reforma, por meio de dois axiomas básicos: a privatização e a redução do gasto público. (DRAIBE apud BRITO et al, 2010, p. 19).

Este modelo de Reforma de Estado passa a ser adotado no Brasil a partir dos anos de 1990 nos governos de Fernando Collor de Melo (1990-1992) e Fernando Henrique Cardoso (19952002). Nesse contexto de reformas e redemocratização, inclusive no setor da educação, percebemos um debate maior acerca da qualidade do ensino, melhoria salarial dos profissionais da educação, defesa da escola pública, gratuita e democrática. De acordo com Bezerra (2008)

\begin{abstract}
Nesse clima ocorreu a intervenção das agências multilaterais no Brasil, intensificada nos anos 1980 e 1990, sobretudo em matéria educacional, ao mesmo tempo em que sucedeu a retomada, no Brasil, das liberdades democráticas, recolocando na ordem do dia nacional a ampliação dos direitos, a democratização da vida e da Administração Pública (p. 42).
\end{abstract}

Os organismos internacionais passam, portanto, a exercer poder político por meio do discurso pautado no consenso na promoção das liberdades democráticas, utilizado para justificar e dar legitimidade às medidas reformadoras por eles sugeridas para as diversas regiões do planeta (SHIROMA, 2004). Dentre a agenda mundial que explicita o discurso para o setor, destacam-se eventos como a Conferência Mundial de Educação para Todos, em Jomtien Tailândia, no ano de 1990; Conferência Nacional de Educação para Todos, em 1993; Conferência Mundial de Educação para Todos, em Dakar, no ano 2000.

Partindo do que foi dito, percebemos a força que as agências multilaterais exercem sobre os países. Conforme Ramos (2004), na linha de ação proposta pelo Banco Mundial o Estado deveria deixar de ser o principal executor das políticas para a área educacional, passando a constituir uma instância coordenadora e controladora. Segundo Siqueira (2004, p. 02)

[...] pelo fato de a educação ter se constituído, na maioria dos países, como um dos direitos sociais, a presença/oferta e o controle da mesma pelo Estado apresentam várias limitações à expansão comercial / mercadológica dos negociadores da educação, tratadas agora como "barreiras" que devem ser derrubadas. Dessa maneira, há uma crescente pressão para que a educação seja tratada, cada vez mais, como uma mercadoria como outra qualquer, regulada pelas normas supostamente "neutras e gerais" do mercado/comércio, sem maiores interferências das regulamentações locais (barreiras). 
No entanto, através da Organização Mundial do Comércio - OMC, ao incorporar o GATT como Acordo Geral que rege o comércio de bens materiais, estabeleceu a lista de 12 serviços e, entre eles, a educação como uma mercadoria. Isto significa a desregulamentação dos direitos sociais e subjetivos conquistados historicamente e a incorporação deste como serviço no ordenamento na lógica do lucro, da oferta e da competição, características do pensamento liberal do "livre" mercado. Nesse sentido, o estudo de Siqueira (2004) destaca que as mudanças que vêm ocorrendo com a redução de recursos públicos têm provocado uma busca crescente de fontes alternativas de fomento e práticas de administração empresarial pelo Estado.

Quanto ao desdobramento da reforma do Estado e da influência dos organismos internacionais na educação nacional, mesmo tendo o país estabelecido no aparato legal a ampliação dos direitos sociais e subjetivos, entre eles, a educação escolar, há que se destacar contradições no marco legal, na concepção e gestão das políticas públicas.

De acordo com KRAWCYZK (2008, p. 51), a Lei de Diretrizes e Bases da Educação Nacional, promulgada em 1996, que deu sustentação à reforma, aumentou a obrigatoriedade da educação de quatro para oito anos, mas limitou todos os direitos consagrados na Constituição Federal de 1988, restringindo o "direito fundamental de todos à educação" ao "direito à educação obrigatória". Além disto, diminuiu a responsabilidade e o papel de Estado no atendimento à educação com a inversão da responsabilidade do Estado em relação à família, colocando-a em primeiro lugar.

Deste modo, denota-se que o Estado se exime da sua responsabilidade de prestar serviços educacionais atribuindo-a às famílias e outros setores como, por exemplo: empresas públicas que foram privatizadas, a ampliação na abrangência de atuação das organizações não governamentais - ONG's e das associações comunitárias. Segundo a Constituição Federal de 1988, o Estado deve constituir um regime de colaboração entre a União, os Estados, o Distrito Federal e os municípios a fim de garantir a universalização do ensino público de qualidade. Na letra da lei, "Na organização de seus sistemas de ensino, a União, os Estados, o Distrito Federal e os Municípios definirão formas de colaboração, de modo a assegurar a universalização do ensino obrigatório". (BRASIL, CF, 1998, Art. 211: § 4ㅇ)

O artigo 8 o da LDB/96 ratifica o que foi exposto acima, assim como estabelece a educação escolar como direito de todos e dever do Estado. No artigo 205 da Constituição Federal/88, temos: "A educação, direito de todos e dever do Estado e da família, será promovida e incentivada com a colaboração da sociedade, visando ao pleno desenvolvimento da pessoa, seu preparo para o exercício da cidadania e sua qualificação para o trabalho".

Ao analisar as contradições presentes no marco legal, concordamos com KRAWCZYK (2008) de que a Carta de1988 viabilizava pela primeira vez o estabelecimento de um sistema nacional de Educação, ao vincular, obrigatoriedade, recursos orçamentários para área e definir um regime de colaboração entre as diferentes instâncias da União pela progressiva obrigatoriedade do ensino básico. No entanto, até os dias atuais este tema não foi objeto de regulamentação pelo Estado nacional.

Segundo Saviani (2009), há quatro obstáculos, persistentes desde a época dos jesuítas, que impedem a concretização do Sistema Nacional de Educação, são eles: a) Financeiro - o grau de prioridade que governos aferem para a educação escolar; b) Política Educacional - a descontinuidade nas políticas onde cada governante quer deixar a sua marca; c) Referencial teórico - os obstáculos ideológicos, as concepções filosóficas a exemplo do positivismo 
(desoficialização do ensino) e liberalismo (afastamento do Estado do âmbito educativo); e d) Legal - a fixação de normas que estabeleça o regime de colaboração.

Sendo assim, para a promoção do direito à educação de qualidade é necessário que haja uma "aliança" entre os diferentes entes federados do Estado Nacional e a sociedade. É preciso emergir um modelo de gestão entendida como coordenação de pessoas e processos na consecução de um projeto (ALARCÃO, 2001).

Enquanto até a década de 80 o planejamento ocupava papel central na ação do Estado, a partir da reforma, Albuquerque (2005) é a gestão que passa a envolver o planejamento. Este último passa a ser entendido como o meio racional a atingir todos os objetivos propostos. Segundo Almeida [et al] (2001, p. 29), o Poder Público passou a utilizar o planejamento, como instrumento balizador de promoção da eficiência e modernização da gestão escolar, garantindo assim um maior acerto nos resultados das práticas educativas desenvolvidas.

Para Ramos (2009) gestão e organização da escola constituem apenas uma dimensão da intricada teia do processo educativo institucionalizado que, por sua vez, está interligado com as demais na perspectiva de coordenador, dar suporte e acompanhar todos os processos e pessoas. Embora se apresentem em diversas configurações.

Numa leitura histórica, a organização da escola no Brasil remonta ao projeto educativo dos Jesuítas, baseado - na Ratio Studiorum (1586-1599), que estabelecia [...] a organização em classes, os horários, os programas e a disciplina. Na atualidade, com a globalização, mundialização e planetarização (DREIFUSS, 2004), a organização da sociedade emerge como desafio à gestão educacional expressa na disputa ideológica entre os conceitos, a citar entre outros, a qualidade total e social.

Com relação à qualidade total esta remete aos interesses do mercado, pautada na racionalização do trabalho, para que o capitalismo atinja sua demanda por produtividade e flexibilidade. Segundo Brito [et al] (2010, p. 57), “[...] alinhada aos interesses do mercado e do Estado reformado, entende a escola como serviço e a educação como mercadoria que deve ser transmitida a todos, inclusive aos mais pobres, desde que disponham de recursos financeiros para obtê-la". E, para tanto, adota práticas empresariais no setor.

Essa concepção de qualidade, pautada no setor empresarial, prima pelo melhor resultado a partir da otimização do processo de produção. Nos planos educacionais, este referencial pretende alcançar melhores resultados com menor custo.

Desse modo, como desdobramento da Reforma do Estado e, conseqüente, adoção desse modelo da qualidade total, a educação escolar passou a ser um serviço prestado por empresas e incrementou princípios mercadológicos de produtividade e rentabilidade, introduzindo a lógica da concorrência. É pertinente destacar que a eficiência passou a ser entendida como prioridade, demonstrando uma mudança conceitual que transforma as relações, ou seja, quem ensina tornou-se um prestador de serviços e quem aprende, cliente.

As escolas, então, passaram a concorrer entre si, seguindo o princípio governamental denominada de meritocracia, ou seja, a instituição que mais se destacasse em relação aos seus resultados educacionais seria premiada seja com reconhecimento institucional e, ou contemplada com recursos financeiros extras.

Em contraposição a esta lógica liberal, há a disputa teórica e política organizada em torno da defesa da educação escolar com qualidade social. "proclamada por movimentos e grupos 
vinculados à luta popular e democrática, resgata a noção da educação como direito humano e social, e a escola como espaço de formação, direito do povo e dever do Estado (BRITO et alli, 2010, p. 57).

Nota-se que, em se tratando de qualidade social, esta se materializa na ação de atender demandas sociais, por meio de mobilizações efetivas em prol da garantia de bens, direitos e serviços. Essa atuação estatal na educação se consubstancia na questão do acesso, permanência e sucesso de todos, portanto, na apropriação crítica dos conteúdos historicamente acumulados.

Percebe-se que essas diretrizes se consolidam na sociedade a partir das ações do Estado, ou seja, das políticas púbicas. Veremos a seguir como a proposta de modernização do Estado e da gestão da educação reafirma ou contradiz tais concepções.

\section{A MODERNIZAÇÃO DO ESTADO E DA GESTÃO DA EDUCAÇÃO: reformas e políticas}

Com o avanço no processo de industrialização nacional, em meados dos anos 1930, a tendência da centralização, da divisão do trabalho, especialização em funções, individualização, impessoalidade, entre outras, reflete diretamente no processo de modernização do Estado e da educação.

A modernização que ocorre no sistema educacional emerge da necessidade de formar pessoas aptas para operarem as máquinas, portanto, para servirem de instrumento para ampliação do mercado, e, conseqüentemente, promover a sua inserção no mundo globalizado.

O Brasil, sendo um país de tradição oligárquica e agrária, marcado por diferenças econômicas, políticas e sociais, iniciou a industrialização nacional tardiamente. Contraditoriamente, apesar do aumento da urbanização e dos postos de trabalho no país, a educação escolar não se tornou uma prioridade ao desenvolvimento nacional.

Segundo KRAWCZYK [et al] (2008)

[...] A expressão mais clara da posição secundária que a educação ocupou nestas circunstâncias pode ser observada nas promessas de expansão do ensino técnico no país, que acabaram se reduzindo a uma ou outra escola estatal e à transferência desse encargo para as entidades representantes da iniciativa privada (p. 50).

Partindo desta assertiva, o avanço nos modelos de gestão vem ocorrendo, embora, ainda apresentem baixos níveis no padrão de qualidade. De acordo com Vidal [et al] (2005, p. 66), "No Brasil, apesar dos avanços registrados nos tempos de democratização, a população usuária da escola pública ainda apresenta baixas exigências quanto a um padrão de qualidade que se coadune com o novo paradigma da sociedade tecnológica e do mundo globalizado".

Para além do novo paradigma e neste a lógica de atender ao mercado, permeada pelo atendimento da demanda de serviços, a qualidade social prima pela apropriação dos conhecimentos historicamente acumulados.

Em sintonia com a conjuntura mundial e nacional, o Estado do Ceará efetiva, em meados da década de noventa, a revisão na estrutura e funcionamento do sistema educacional, pela reforma administrativa de cunho gerencial, pela revisão do marco legal e com a implementação de políticas públicas. Tal esforço objetivou modernizar e racionalizar a máquina administrativa adequando-a ao modelo de gestão flexível, que permitisse enxugar custos operacionais e 
fomentar uma nova cultura institucional alinhada a novas formas da gestão do sistema e da escola (RAMOS, 2009).

A gestão colegiada proposta pelo governo Avançando nas Mudanças (1995-1998) reorganiza o modelo da gestão educacional adotando no governo ações concretas e viáveis, são elas:

- As eleições para diretores das unidades escolares;

- A dinamização e, ou, formação das organizações escolares;

- A implantação dos conselhos escolares;

- A capacitação continuada e em serviços dos gestores educacionais, através de metodologias participativas e do 'aprender fazendo' (CEARÁ: PDS/SEDUC 95/98, p. 05).

Com relação à eleição, é fato que os governos vêm desenvolvendo esta

Política. No entanto, A eleição por si só, entretanto, não garante um processo democrático (RAMOS, 2004, p. 189), pois é preciso combinar mecanismos de participação direta e representativa, bem como procedimentos pontuais e sistemáticos que promovam práticas pautadas em valores democráticos e solidários na consecução do projeto de escola-comunidade com qualidade.

Como organismo de participação representativa, a partir do ano de 1997 os conselhos escolares foram implantados efetivamente em 625 unidades escolares da rede estadual de ensino, desempenhando as funções consultivas, normativas, deliberativas, além de fiscalizar e avaliar o projeto educativo da escola (CEARÁ, MENSAGEM, 1998).

Segundo análise do Secretário de educação deste governo, Antenor Naspolini,

Nós temos Conselhos e conselhos! Uns conselhos que atuam muito bem e uns conselhos que simplesmente são do Amém! Do Amém porque simplesmente assina o que o diretor quer; não é um conselho, é um órgão do amém! Ele tem que ser um órgão próprio, não é um órgão também contra a direção. É um órgão de cooperação com a direção. (apud RAMOS, 2004, 132).

Considerando esta realidade contraditória, no estudo sobre gestão democrática, Ramos (2004) afirma que há uma recentralização na gestão da educação básica estadual no Ceará. Para Cely, assessora da SEDUC, "Descentralizo aqui, mas alguém centraliza lá", ou seja, o que tem ocorrido é uma mudança no lócus de centralização.

Ao analisar a norma, procedimentos, representatividade, formação, bem como a relação entre SEDUC - Núcleo Gestor e Conselho Escolar, a autora destaca que não há uma política de Estado que viabilize as condições objetivas de participação direta e representativa ${ }^{1}$ e propõe constituir as Assembléias Escolares como órgão máximo deliberativo da escola, o Conselho Escolar como órgão deliberativo imediato e o Núcleo Gestor, por sua vez, um órgão executivo, tendo como atribuição encaminhar as decisões tomadas nas Assembléias e no Conselho (RAMOS, 2004).

\footnotetext{
1 Para ilustrar, a política da rede municipal de ensino de Fortaleza incentiva e garante as condições objetivas da participação docente na gestão da escola, pois, quando na presidência do Conselho Escolar o professor terá, conforme Portaria no. 11/2008 da SME, 50\% da sua carga horária de trabalho a serviço do conselho, prioritariamente no turno da tarde.
} 
Nestas experiências históricas, podemos perceber no Estado do Ceará, a presença de características na gestão tecnocrática e democrática, de cunho liberal. De acordo com Saviani apud RAMOS (2009), as escolas se desorganizam ainda mais, o que era próprio do Regime Militar, como a gestão tecnocrática, passou haver fragmentação e descontrole, em nome da descentralização adotada no liberalismo.

Em consonância com a reforma do Estado nacional, as políticas locais possibilitaram aos gestores maior flexibilidade e autonomia na utilização dos recursos financeiros, ao mesmo tempo em que responsabiliza o diretor, tanto do controle externo do trabalho, da implementação de mudanças, quanto dos resultados de aprendizagem, como veremos a seguir.

No tocante à gestão democrática, princípio constitucional prescrito ao ensino público, na forma da lei (BRASIL/LDB, 1996, art. 206), ou seja, dispositivo legal que se constitui como uma lei de eficácia limitada, por necessitar de legislação ulterior, ratifica a tese de que há uma desregulação controlada por parte do Estado, pois um princípio fundante para o exercício da democracia, estabelecido desde 1988, até os dias de hoje não foi objeto de normatização.

Para além do marco legal, a participação efetiva da sociedade em espaços institucionalizados do setor são quase sempre pautados por procedimentos pontuais e assistemáticos, a citar: eleição para dirigente escolar, eleição para representante do conselho escolar, do grêmio, da associação, etc. Estes organismos escolares, criados para democratizar as relações de poder, são ressignificados e passam a atuar como instituições que legitimam a vontade de poucos (RAMOS, 2004), ao invés de se constituir em um instrumento onde sociedade civil e Estado debatem ideias e propostas e negociam prioridades quanto à formulação e execução das políticas públicas e do projeto de escola.

Com a reeleição de Tasso Jereissati, em 1998, os princípios norteadores das gestões anteriores - sustentabilidade; visão de longo prazo; participação e parceria; descentralização; e qualidade - são ratificados no documento Consolidando o Novo Ceará. Plano de Desenvolvimento Sustentável - 1999/2002 (CEARÁ, 2000).

Com relação à parceira, a SEDUC firmou um empréstimo com Banco Internacional de Reconstrução e Desenvolvimento - BIRD (Contrato de Empréstimo de número 4591 - BR), em 2002, para viabilizar o Projeto Escola do Novo Milênio - PENM com o objetivo de assegurar um padrão de qualidade, eficiência e equidade na prestação dos serviços; ampliar o acesso à educação e fortalecer a capacidade gerencial e pedagógica dos níveis central, regional, municipal e escolar para oferecerem, com eficiência, os serviços de educação básica (CEARÁ, Relatório do PENM, 2005, 08).

Este convênio se constituiu por cinco componentes, são eles: Melhoria da qualidade e eficiência escolar; Ampliação de acesso; Programa de Desenvolvimento da Educação Municipal (PRODEM); Descentralização e fortalecimento institucional e Financiamento da gestão do projeto.

Estes componentes visavam promover a sustentabilidade social do processo educacional a partir de uma mobilização ampla, com foco na escola pública que temos e na que queremos. Esta última, para ilustrar, se traduzia na Escola Viva ${ }^{2}$, comprometida com o sucesso do aluno de modo

2 Segundo Naspolini (2001, p.179) [...] a escola está cada vez mais VIVA, valendo destacar 51 escolas de Fortaleza e 110 no interior do estado onde a música, as artes plásticas, a dança, o teatro e a informática educativa compartilham o dia-a-dia de alunos e professores, tornando criativo e interessante o ato de aprender e de ensinar. 
prazeroso, alegre, dinâmico, crítico e criativo (CEARÁ, PLANO, 2001).

O projeto Escola Viva reafirma o princípio das parcerias e propõe a ação interinstitucional, com envolvimento dos setores da educação, ação social, saúde, cultura e ciência e tecnologia, transformando a escola no pólo de uma comunidade de aprendizagem, em escolas pilotos. Parafraseando Pablo Gentili, destacamos que qualidade para poucos não é qualidade, é privilégio.

Na promoção da mobilização social, este governo organizou o Congresso Estadual Escola do Novo Milênio de 20 a 22 de março de 2002, onde foram formuladas propostas de Políticas para a Educação Básica no Estado do Ceará e revisão dos instrumentos de planejamento. Segundo o governo,

O Congresso Estadual A Escola do Novo Milênio caracterizou-se como ponto de chegada da caminhada vivenciada pelos educadores cearenses na última década e como ponto de partida para o Plano Decenal da Educação Básica, que definirá os rumos da Educação na escola, uma atualização/revisão do Projeto Político Pedagógico (PPP), do Plano de Desenvolvimento da Escola (PDE) e do Regime Escolar (Código de Ética). (CEARÁ, Congresso Escola do Novo Milênio, Abril, 2002, 05).

Mesmo contanto com a participação ampla da comunidade escolar, a partir dos encontros nas escolas e nas regiões, vale ressaltar que houve veto à participação do movimento social organizado na área da educação e de teóricos que divergiam da política, pois só era permitida a entrada de convidados especiais com credenciais.

Percebemos então, a manutenção dos mesmos princípios de mobilização social, parceira, qualidade, entre outros, do governo anterior. Vale ressaltar que a partir desse governo, há ênfase no fortalecimento da capacidade gerencial dos níveis central, regional, municipal e escolar.

Nesta perspectiva, o convênio firmado com o BIRD possibilitou a consolidação de padrões básicos de funcionamento das escolas através da construção, reforma e adaptação do parque escolar, aquisição de material didático-pedagógico, a implementação da Gestão Integrada da Escola, como veremos a seguir, em $100 \%$ das unidades.

Com essas diretrizes políticas desses governos

Busca-se reduzir e subordinar a prática do ensino-aprendizagem à exterioridade, a partir da adoção de regras e da utilização de um suporte material (livros, mídia instrucional, parâmetros) que se quer prescritivo, estandartizado e, por isso, mesmo passivel de ser classificado, mensurado, comparado, sempre com a finalidade de cumprir metas. (LÓPES, LOPEZ, 2010, p. 97).

Esta tese é ratificada pelo diretor Glauber da Escola Paulo Benevides reafirma na entrevista ao citar que "[...] na Escola do Novo Milênio as ações implementadas melhoraram algumas coisas em termos de material". Em outras palavras, a modernização e o fortalecimento institucional caracterizou-se como a modernização tecnológica.

Em Vida Melhor, Escolar Melhor, programa de governo para o setor da Educação no período de 2003 a 2006, destaca-se a Modernização e Melhoria da Educação Básica que passa a ser considerada como uma necessidade intrínseca do sistema, uma forma de perseguir os princípios de qualidade e equidade. Nesse sentido, é definido conceitualmente e adotado um conjunto de estratégias e ações que têm como foco a modernização da gestão educacional e a melhoria da educação cearense. (CEARÁ, SEDUC, 2006). 
As políticas de modernização da gestão nesse governo podem ser sintetizadas em três aspectos:

a) MODERNIZAÇÃO DOS PROCESSOS DE GESTÃO:

* Gestão Integrada da Escola (GIDE) - adotada como instrumento de planejamento institucional que congrega os diferentes até então vigentes, ou seja, Projeto Político Pedagógico (PPP), Plano de Desenvolvimento da Escola (PDE) e Programa de Modernização e Melhoria da Educação Básica (PMMEB), que buscam integrar as dimensões pedagógicas, estratégicas e da gestão, pautando pela melhoria dos resultados e o monitoramento externo da unidade escolar. O princípio da política púbica enquanto diretriz de que esta deve ser elaborada de maneira coletiva pela comunidade se contradiz com a fala do diretor Glauber da escola:

Eu não vi nenhum efeito prático daquilo. Foi uma cópia do projeto de Minas Gerais que o Lúcio Alcântara trouxe na época. Os mineiros "tavam" tudo por aqui. Eles davam curso dessa GIDE para saber como fazer. Eu mesmo participei de uns três ou quatro encontros SEFAZ. Mas assim, foi muito dinheiro gasto com o projeto, com o trabalho, sem efeito. Quando precisei usar alguma coisa da GIDE, eu "tive" que fazer um projeto pra entregar à SEDUC. la lá na GIDE, tirava uma cópia do espaço onde tinha aquela ação, porque se não tivesse aquela ação na GIDE, também o dinheiro não vinha. Aí eu ia lá, fazia aquela ação "todinha" para entregar lá. E às vezes nenhum recurso chegava na escola, nada.

* Formação Continuada de Gestores incutindo nos diretores eleitos pela comunidade princípios e práticas empresariais da gestão para o sucesso escolar, ou seja, a qualidade total. Nesta destacase a ênfase da gestão nas funções gerenciais em detrimento das questões centrais pedagógicas, que são a razão de ser da instituição.

Essas mudanças operadas nos instrumentos de planejamento e da gestão incorporaram conceitos das novas formas de administração, a qualidade total, planejamento estratégico, gestão por resultados. Esses conceitos fazem parte do mesmo paradigma da gestão de qualidade total (GQT), ao enfatizar os resultados em detrimento das condições históricas, objetivas, econômicas e culturais em que a política está inserida.

Segundo Albuquerque (2005, p. 219), no campo educacional, a ênfase da abordagem estratégica de planejamento da ação governamental cearense, no período 1995/2002, se manifestou através de prática refuncionalizada, na qual tal refuncialização do planejamento elenca velhas práticas e incorpora outras abordagens de inclinações mais inovadoras, o que corroborou para seu caráter pragmático.

b) FERRAMENTAS DE SUPORTE À GESTÃO: São programas para atender tanto a comunidade escolar quanto a civil e que visam integrar os programas escolares com as diretrizes educacionais. São elas:

* Diretrizes para a Educação Básica - oferece orientações administrativas e pedagógicas do ano letivo;

* Sistema de Acompanhamento e Desempenho da Rotina Escolar (SADRE): se caracteriza como uma ferramenta computacional de suporte tecnológico que proporciona: a) a comunicação entre todos que estão diretamente envolvidos com a escola; b) a criação de fluxo de informações e troca de experiências subsidiando a tomada de decisões pedagógicas e gerenciais; c) a realização de atividades colaborativas, cujas produções permitam enfrentar os problemas, entre outras;

* Sistema Integrado de Gestão Educacional (SIGE) é um sistema que informatiza os setores e os 
principais processos administrativos da Secretaria de Educação Básica do Estado do Ceará. FORTALECIMENTO DO CONTROLE SOCIAL:

* Conselhos escolares: organismo que congrega representantes de toda a comunidade escolar e visa promover a autonomia a partir da discussão, deliberação, execução e o controle social da escola.

* Grêmios: é uma organização autônoma, de responsabilidade dos estudantes, tem papel importante nas gestões democráticas estando em busca das reivindicações dos alunos e da melhoria da qualidade de ensino. (CEARÁ, SEDUC, 2006). Os grêmios devem juntamente com os conselhos escolares desenvolver ações sistemáticas, em que haja a participação de toda a comunidade; estas atividades devem estar ligadas ao núcleo gestor da escola.

Dialogando com o gestor da Escola Deputado Paulo Benevides sobre a relação entre o Slogan Escola Melhor, Vida Melhor e as políticas educacionais implementadas no período em tela, ele cita que

\begin{abstract}
Uma Escola Melhor e Vida Melhor é, a gente ainda tem que melhorar muita coisa dentro da escola para que seja um Escola Melhor, uma Vida Melhor. Tem que trabalhar não só com a educação dos filhos, mas com a educação dos pais também. [...]. Porque a educação não acontece só na escola não. Você também tem que ter também em casa. Então, a partir do momento em que você tiver uma, uma sociedade mais educada assim, culturalmente mais educada, você vai ter uma escola melhor e uma vida melhor mesmo, com certeza (Prof. e diretor da escola Glauber).
\end{abstract}

Percebemos, portanto, que existem contradições entre o que consta nos objetivos programáticos dos governos do Estado do Ceará, ou seja, nas diretrizes da política pública e a prática da gestão pública da educação, como desvela o estudo de caso instrumental da escola Deputado Paulo Benevides.

Diante das iniciativas desses Governos podemos notar as ações que vêm sendo desenvolvidas para a melhoria e modernização da gestão nos moldes da GQT e a modernização entendida como mudança nos procedimentos, ou seja, instrumentos de planejamento, adotando práticas empresariais de avaliação por resultados. Dentre os desdobramentos da reforma do Estado na educação escolar cearense destaca-se a ênfase na gestão em detrimento do planejamento, que passa a ser entendido como uma etapa do gerenciamento.

Em síntese, desvelamos através da revisão do marco legal, da concepção e gestão das políticas educacionais que o modelo político adotado pelo Governo das Mudanças toma como referencial a qualidade total e nesta, a gestão passa a ocupar uma centralidade em detrimento do planejamento.

\title{
CONSIDERAÇÕES FINAIS
}

Podemos perceber que com a reforma do Estado brasileiro, a política neoliberal adotada resultou, na área educacional, em medidas de descentralização, no que diz respeito a promoção do serviço público, à gestão e ao financiamento, em que o poder público atribui a outros setores responsabilidades que lhe eram inerentes, como ocorre nas privatizações e na publicização, onde 
é atribuído ao setor privado e às organizações públicas não estatais responsabilidades inerentes à função do Estado de direito. Dentre os serviços, destaca-se a educação escolar como mercadoria.

Nos diferentes governos em estudo, no setor educacional, percebe-se a sintonia nas diretrizes políticas na modernização da gestão pautada pelo fortalecimento do controle social e institucional. $O$ primeiro governo enfatiza a participação popular e destaca o procedimento pontual da eleição de diretores escolares e a criação de organismos escolares inertes - sem vida pois não foram criadas as condições objetivas e econômicas para a participação da comunidade escolar no planejamento, execução e monitoramento do projeto político- pedagógico-PPP, pois não há apoio institucional. O segundo governo inverte a lógica do planejamento institucional ao adotar um Convênio como definidor da ação do Estado - Projeto Escola do Novo Milênio - e o terceiro culmina com a modernização tecnológica ao informatizar os dados que possibilitam o controle externo do trabalho escolar e neste, a implementação da GIDE, que toma como centralidade a gestão para o sucesso escolar e secundariza a importância do planejamento.

Sendo assim, contraditoriamente, esses governos "[...] combinam duas razões, aparentemente contraditórias: a centralização e a descentralização" (ALBUQUERQUE, 2008, p. 31). Centralizam o controle externo na avaliação dos resultados, possíveis com a modernização tecnológica e as ferramentas de suporte e gestão. Descentraliza a elaboração e execução da proposta pedagógica.

Sendo assim, as diretrizes políticas do Governo do Estado do Ceará afirmam a centralidade da gestão, ao mesmo tempo em que a concepção democrática, explicitada na política educacional, nem sempre se efetivou na prática, pois ela representa mais uma mudança do padrão vigente, conforme explicita Ramos (2004) em seu estudo sobre a eleição de diretores no Governo Das Mudanças (1995-2004). Neste sentido, destaca-se a promoção da recentralização, ou seja, a mudança de lócus do centro.

Quanto aos instrumentos de planejamento destacam-se a elaboração e aplicação de diferentes instrumentos a partir de cada ação no interior da escola e a sistematização da GIDE que congrega todos os demais. No entanto, nesse ínterim, percebe-se que o planejamento é refuncionalizado e passa a ser parte integrante da gestão, ou seja, uma etapa do gerenciamento.

Sendo assim, concluímos que a centralidade da política destes governos do PSDB no Ceará (1995-2006) é o fortalecimento institucional, ou seja, da capacidade gerencial dos níveis central, regional, municipal e escolar para oferecerem, com eficiência, os serviços de educação básica (CEARÁ, Relatório do PENM, 2005, 08). Adota-se como referencial a gestão da qualidade total como parâmetro passível de classificar, mensurar e comparar as unidades escolares, materializando, portanto, a reforma do Estado proposta nacionalmente.

Concluímos, reafirmando a tese de Nora Rut Krawczyk $(2003,177)$ ao analisar as reformas educacionais em três Estados, Ceará, São Paulo e Paraná, de que a centralidade dessas reformas na estrutura física, nos recursos pedagógicos e no fortalecimento da gestão, conforme citamos acima, de que [...] transformar a escola significa não só mudar a dinâmica no interior dela, mas também, e ao mesmo tempo, mudar a lógica de todo o sistema.

\section{REFERÊNCIAS BIBLIOGRÁFICAS}

ALARCÃO, Isabel. Escola reflexiva e nova racionalidade. Porto Alegre, Artmed, 2001. 
ALBUQUERQUE, Maria Gláucia M. T. Planejamento educacional no Ceará (1995-2002): a escola como ponto de partida. Tese (Doutorado) - Universidade Federal do Ceará, 2005.

BEHRING, Elaine Rossetti. Brasil em contra-reforma: desestruturação do Estado e perda de direitos. São Paulo: Cortez, 2003.

BEZERRA, José Eudes Baima. Crise, reforma do Estado e gestão da educação: o que dizem as diretrizes das instituições multilaterais? In: ALBUQUERQUE, Gláucia Menezes Teixeira (Org.). Fortaleza, Ed.UECE, 2008.

BRESSER PEREIRA, Luís Carlos. A reforma do Estado dos anos 90: Lógica e Mecanismos de Controle. 1997.

BRITO, Célia Maria Machado de. Estrutura e Financiamento da Educação Básica. Célia Maria Machado de Brito [et al]. Fortaleza: RDS, 2010.

BRASIL. Constituição Federal de 1988.

BRASIL. Lei de Diretrizes e bases da educação nacional, no. 9.396/1996.

CEARÁ. Secretaria da Educação Básica do Ceará. Gestão escolar e qualidade da educação. Fortaleza: SEDUC, 2005.

Todos pela educação de qualidade para todos. № 01.

Secretaria da Educação, 1995-1998.

. Educação básica de qualidade no Ceará/ Escola do Novo Milênio.

Secretária da educação básica, 1999-2002.

. Congresso Escola do Novo Milênio. 2002. Mineografado.

2005.

. Relatório de Progresso Projeto Escola do Novo Milênio (2001-2005). Mineografado.

. Plano de educação básica/ Escola melhor, vida melhor.

Secretaria da Educação Básica, 2003-2006.

KRAWCZYK, Nora Rut. A escola média: um espaço sem consenso. Cadernos de Pesquisa, no. 120, p. 169-202, novembro, 2003.

KRAWCZYK, Nora Rut. VIEIRA, Vera Lúcia. A reforma educacional na América Latina: uma perspectiva histórico-sociológica. São Paulo: Xamã, 2008.

LOPES, Alice Casimiro. LÓPEZ, Silvia Brãna. A performatividade nas políticas de currículo: o caso do ENEM. Educação em revista, Belo Horizonte, V. 26, no. 01, Abril, 2010, p. 89-110.

RAMOS, Jeannette Filomeno Pouchain. A Reforma do Estado e seus desdobramentos no planejamento e na gestão da escola de ensino cearense: estudo de caso da Escola Dep. Paulo Benevides (1995-2006). Jeannette Filomeno Pouchain Ramos [et al]. Fortaleza, 2001. 
RAMOS, Jeannette Filomeno Pouchain. Estado e Educação: O papel do Estado e a política de descentralização da Educação na América Latina segundo os organismos internacionais. Fortaleza, 2002, mimeografado.

RAMOS, Jeannette Filomeno Pouchain. Tradições e contradições no projeto educativo da escola média. Tese de doutoramento em Educação Brasileira, Universidade Federal do Ceará, 2009.

Pela Obrigatoriedade Do Ensino Médio, Sim! 10 argumentos contra para justificar a obrigatoriedade. Mimeografado, out, 2009. (Ver site: www.educas.com.br)

Projeto educativo e político-pedagógico da escola de ensino médio: Tradições e contradições na gestão e na formação para o trabalho. Fortaleza: UFC, 2009.

. Gestão democrática da escola pública: a experiência do governo das mudanças.

Fortaleza: UECE, 2004.

SAVIANI, Demerval. Sistema de educação: subsídios para a Conferência Nacional de Educação (Conae) QUEIROZ, Arlindo Cavalcanti. GOMES, Leda (Org.). Conferência Nacional de Educação (Conae), 2010- Reflexões sobre o Sistema Nacional Articulado de Educação e o Plano Nacional de Educação. INEP, Brasília, 2009.

SIQUEIRA, Angela C. A regulamentação do enfoque comercial no setor educacional via OMC/GATS. Revista Brasileira de Educação, n² 26, págs 145-184, 2004.

SHIROMA, Eneida Oto. Implicações da política de profissionalização sobre a gestão e o trabalho docente. S. I., 2004.

VIDAL, Eloísa Maia. O passo e o compasso: caminhos da modernização da gestão escolar no Ceará. Eloísa Maia Vidal [et al]. In: CEARÁ, Secretaria da Educação Básica. Gestão escolar e qualidade da educação, Fortaleza: SEDUC, 2005.

SAVIANI, Dermeval. Sistema de educação: subsídios para a Conferência Nacional de Educação (Conae) QUEIROZ, Arlindo Cavalcanti. GOMES, Leda (Org.). Conferência Nacional de Educação (Conae), 2010- Reflexões sobre o Sistema Nacional Articulado de Educação e o Plano Nacional de Educação. INEP, Brasília, 2009. 